\title{
Corporate Debt, Hybrid Securities and the Effective Tax Rate
}

\author{
PAOLO M. PANTEGHINI
}

CESIFO WORKING PAPER NO. 2329

CATEGORY 1: PUBLIC FinANCE

JUNE 2008

\footnotetext{
An electronic version of the paper may be downloaded

- from the SSRN website: www.SSRN.com

- from the RePEc website: - from the CESifo website: 


\title{
Corporate Debt, Hybrid Securities and the Effective Tax Rate
}

\begin{abstract}
In this article we use contingent-claim analysis to calculate the effective tax rate (ETR) under corporate debt finance. In particular, we deal with both pure debt and two of the most wellknown hybrid securities, i.e., convertible, and reverse convertible bonds. We show that: 1) effective taxation crucially depends on the characteristics of debt, and 2) existing measures of ETR can be dramatically biased, since they do not account for debt maturity, default risk or the ability to convert debt into equity.
\end{abstract}

JEL Code: H2.

Keywords: capital structure, contingent claims, corporate taxation, hybrid securities.

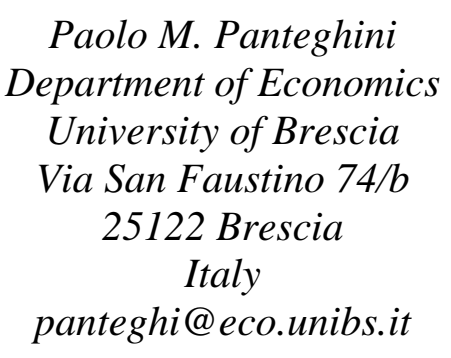

The author wishes to thank Robert Casarin for his helpful support in MATLAB computations, and Alessandro Bucciol for excellent research assistance. 


\section{Introduction}

Forward-looking measures of effective taxation aim to measure the impact of taxation on investment projects, given specific assumptions on future taxation and corporate strategies. ${ }^{1}$ Although forward-looking effective tax rates (ETRs) should be based on future hypothetical behaviour, quite surprisingly, the existing indicators do not take into account many future events, that usually characterize a company's life. In particular, though it is recognized that the choice of a financial source can affect the value of an investment project, existing literature provides a poor analysis of financial aspects. To our knowledge, existing measures of ETR usually disregard debt maturity, the existence of collateral, as well as a company's ability to issue hybrid securities. These limits are recognized by Devereux (2003), who says that "there are many other forms of financial contract that have elements of debt and equity finance by which a company can raise finance. These include, for example, swaps and various forms of option that the literature on measuring effective tax rates has not yet incorporated".

The aim of this article is to provide a theoretical framework that enables us to calculate ETRs under different kinds of debt finance. To do so, we will apply a standard contingent-claim model and will calculate the ETR under two forms of debt finance, i.e., secured and unsecured debt. Moreover, we will measure the ETR under the assumption that a company issues well-known hybrid securities, such as convertible and reverse convertible bonds. ${ }^{2}$ We will therefore show that effective taxation crucially depends on the characteristics of debt, and the ability to convert debt into equity. ${ }^{3}$ Moreover, we will see that, by disregarding expected future events, the existing measures of ETR are dramatically biased.

The structure of this article is as follows. Section 2 introduces the model and discusses its assumptions. Section 3 provides a measure of the ETR under both secured and unsecured debt finance. Section 4 measures the ETR by assuming the issue of convertible and reverse convertible bonds. Section 5

\footnotetext{
${ }^{1}$ For a discussion on effective tax rates and their applications, see e.g. Giannini and Maggiulli (2002), and Sørensen (2003).

${ }^{2}$ Our approach is similar to that applied by Gray et al. (2008), who provide a contingent-claim analysis of public sector debt sustainability.

${ }^{3}$ It is well-known that hybrid securities are often issued to avoid taxation (see, e.g., McDonald, 2004) and to reduce agency conflicts (see, e.g., Hennessy and Tserlukevich, 2005; Ross, 2005). However, these topics are beyond the scope of this article.
} 
provides some numerical results. Section 6 summarizes our main findings, and proposes some possible extensions.

\section{The model}

In this section we introduce a model describing the financial and investment strategies of a risk-neutral company. We assume that a company starts to earn a payoff $\Pi_{t}$ once a depreciable investment cost, denoted as $I$, has been paid. ${ }^{4}$ This payoff evolves according to the following geometric Brownian motion

$$
d \Pi_{t}=\sigma \Pi_{t} d z_{t}, \text { with } \Pi_{0}>0,
$$

where $\sigma$ is the instantaneous standard deviation and $d z_{t}$ is the increment of a standard Wiener process. ${ }^{5}$ For simplicity, hereafter we will omit the time variable.

Capital markets and debt Let us first assume that risk is fully diversifiable, credit markets are perfectly competitive, and information is symmetric.

As regards debt, we know that it may cause both costs and benefits. On one hand, debt finance may lead to default ${ }^{6}$ and agency conflicts between shareholders and debtholders. On the other hand, the tax deductibility of interest payments ensures a saving to levered companies (Modigliani and Miller, 1963; Leland, 1994). ${ }^{7}$

When a company does not meet its debt obligation, default takes place. In this case, shareholders are expropriated by the lender. Let us next define

\footnotetext{
${ }^{4}$ For simplicity, we assume that a firm cannot postpone its investment decision. For a joint analysis of intertemporal and financial choices, see Panteghini (2007a and 2007b).

${ }^{5}$ The general form of the geometric Brownian motion is $d \Pi_{t}=\alpha_{\Pi} \Pi_{t} d t+\sigma \Pi_{t} d z_{t}$ where $\alpha_{\Pi}$ is the expected rate of growth. If shareholders are risk neutral, in equilibrium we have $\alpha_{\Pi}=r-\delta$, where $r$ is the risk-free interest rate and $\delta$ is the so-called convenience (or dividend) yield. For simplicity, in (1) we assume that $\alpha_{\Pi}=r-\delta=0$. For further details see McDonald and Siegel (1984 and 1985).

${ }^{6}$ Default is costly. Branch (2002) classifies default costs in four categories: 1) costs borne directly by the bankrupt firm; 2) costs faced directly by the claimants; 3) losses to the bankrupt firm that are offset by gains to other entities; 4) costs born by thirdparty entities. By accounting for these categories he estimates a total default-related cost ranging between $12.7 \%$ and $20.5 \%$.

${ }^{7}$ For simplicity we disregard non-tax benefits related to the fact that debt can reduce agency conflicts between managers and shareholders (Jensen, 1986).
} 
$C \leq \Pi_{0}$ as the coupon paid to the lender, and introduce the following:

Assumption 1 At time 0, the company borrows some resources and pays a coupon $C$, which is not renegotiable.

Assumption 2 If $\Pi$ drops to a threshold value, default occurs.

Assumption 3 The cost of default is $v C$ with $v>0$.

In line with Leland (1994), Assumption 1 means that a company sets a coupon and then calculates the mark-to-market value of debt. In the absence of arbitrage, this is equivalent to calculating the effective interest rate for a given amount of nominal debt. ${ }^{8}$ For simplicity, we also assume that debt cannot be renegotiated: this means that we apply a static model, where a company's financial policy cannot be reviewed later. ${ }^{9}$ Assumptions 2 and 3 introduce the risk and the cost of default, respectively. Given (1), it is assumed that, if a company's payoff falls to a given threshold value, the company cannot meet its obligation and is thus expropriated by the lender (Assumption 2). In the event of default, the lender faces a sunk cost, that is proportional to the coupon paid (Assumption 3).

To make the model more general we also assume that the lifetime of an investment project is finite. Thus we introduce the following:

Assumption 4 Following a Poisson process, at any time there is a probability $\lambda d t$ that the existing project dies during the short internal dt.

Assumption 4 introduces stochastic decay of capital, and thus entails that the expected lifetime of an investment project is finite, although uncertain. ${ }^{10}$

\footnotetext{
${ }^{8}$ This means that the ratio between the coupon $C$ and the mark-to-market value of debt is equal to the effective interest rate (i.e., the risk-free interest rate plus the default premium).

${ }^{9}$ For a detailed analysis of dynamic strategies, with costly debt renegotiation, see e.g. Goldstein et al. (2001), and Hennessy and Whited (2005).

${ }^{10}$ The quality of results would not change under deterministic depreciation. As shown by Dixit and Pindyck (1994), assuming a Poisson process gives the same result as assuming a deterministic exponential decay of capital.
} 
Taxation Let us next focus on tax rules and introduce the following:

Assumption 5 Interest payments are fully deductible.

Assumption 6 Fiscal depreciation allowances are equal to $\lambda_{F} \gtrless \lambda$ times the investment cost $I$.

Assumption 7 Before default, the lender's relevant tax rate is zero.

Assumption 8 The tax system is fully symmetric.

Assumption 5 introduces the tax benefit of interest deductibility. ${ }^{11}$ Assumption 6 states that fiscal depreciation allowances may differ from economic depreciation. Assumption 7 accounts for the fact that in most cases, the tax burden on capital income is relatively low or even close to zero. In this model the lender's tax rate is equal to zero for simplicity. Notice however that, after default, the lender becomes shareholder and is thus subject to corporate taxation. Assumption 8 allows us to analyze the effects of taxation in a symmetric framework. ${ }^{12}$ Given these assumptions we can write a company's after-tax payoff as:

$$
\Pi^{N}(\Pi ; C)=(1-\tau)(\Pi-C)+\tau \lambda_{F} I .
$$

Let us next calculate the value of equity and debt. Using dynamic programming, we can write the value of equity as the sum between the after-tax payoff received in the interval $d t$, i.e., $\Pi^{N}(\Pi ; C) d t$, and the value function after the time interval $d t$ has passed: ${ }^{13}$

\footnotetext{
${ }^{11}$ For simplicity, we do not account for rules aimed at limiting the deductibility of interest payments, such as thin capitalization rules. Notice also that in 2008, both Germany and Italy have abandoned thin capitalization rules and introduced a new constraint on interest deductibility. According to this new device, if the amount of interest paid exceeds a given percentage of EBITDA (30\%), the exceeding part of interest payment is non-deductible, but can be carried forward. For further details see, e.g., Eckhardt (2007) and Galeano and Rhode (2008).

${ }^{12}$ We leave the analysis of tax asymmetries for future research.

${ }^{13}$ As shown by Niemann and Sureth (2005), under risk neutrality, contingent claim analysis and dynamic programming lead to identical investment rules. For further details on mathematical steps see Panteghini (2006, 2007a).
} 
$E(\Pi ; C)= \begin{cases}0 & \text { after default } \\ \Pi^{N}(\Pi ; C) d t+(1-\lambda d t) e^{-r d t} \xi[E(\Pi+d \Pi ; C)] & \text { before default. }\end{cases}$

As shown in (2), at any period $d t$, there is a probability $\lambda d t$ that the project dies, and that the value of equity goes to zero. Following the same procedure we can calculate the mark-to-market value of debt:

$$
D(\Pi ; C)=\left\{\begin{array}{cc}
{\left[(1-\tau) \Pi+\tau \lambda_{F} I\right] d t} & \text { after default } \\
+(1-\lambda d t) e^{-r d t} \xi[D(\Pi+d \Pi ; C)] & \\
C d t+(1-\lambda d t) e^{-r d t} \xi[D(\Pi+d \Pi ; C)] & \text { before default. }
\end{array}\right.
$$

As can be seen, the value of debt is contingent on the event of sudden death of capital. Since there is a probability $\lambda d t$ that a company's profit goes to zero, in this case, the lender's claim becomes worthless. This means that, given Assumption 4, debt maturity is in line with the expected lifetime of investment. ${ }^{14}$ Notice that, by assuming this fact, we depart from most of the existing tax literature, which usually assumes that investment is financed only by default-free short-term debt, irrespective of a project's expected lifetime and riskiness (see, e.g., Devereux and Griffith, 1999).

Using (2) and (3) we can calculate a company's Net Present Value (NPV), i.e.,

$$
V(\Pi ; C)=E(\Pi ; C)+D(\Pi ; C)-I .
$$

Using (4) and setting $\tau=0$, we can also calculate the NPV in the absence of taxation, denoted as $V_{P T}(\Pi ; C)$. As pointed out by Devereux and Griffith (1999), a natural measure of the ETR would be $\frac{\left[V_{P T}(\Pi ; C)-V(\Pi ; C)\right]}{V_{P T}(\Pi ; C)}$. However, this ratio would be undefined if $V_{P T}(\Pi ; C)=0$. For this reason they propose to scale the numerator by the present value of the pre-tax income stream, net of depreciation. Following their advice, we calculate the effective tax rate as the ratio between the difference $\left[V_{P T}(\Pi ; C)-V(\Pi ; C)\right]$ and the present

\footnotetext{
${ }^{14}$ Graham and Harvey (2001) show that more than $63 \%$ of the US firms surveyed state that debt maturity is aimed at matching with assets' lifetime. Therefore, our assumption is realistic.
} 
value of future payoff, net of depreciation, i.e. ${ }^{15}$

$$
E T R=\frac{\left[V_{P T}(\Pi ; C)-V(\Pi ; C)\right]}{\frac{\Pi-\lambda I}{r+\lambda}} .
$$

In the following sections, we will apply Formula (5) to measure the ETR under different financial strategies.

\section{Pure debt}

In this section we focus on pure debt finance. Following Smith and Warner (1979), and Leland (1994) let us introduce two different definitions of default: ${ }^{16}$

Definition 1 Under secured debt finance, default occurs when $\Pi$ falls to an exogenously given threshold point $\widetilde{\Pi}^{s}$.

Definition 2 Under unsecured debt finance, the threshold point, denoted as $\widetilde{\Pi}^{u}$, is chosen optimally by shareholders at time 0 .

According to Definition 1, default may be triggered when a company's payoff falls to the exogenously given threshold point $\widetilde{\Pi}^{s}$. This definition refers to secured debt, where default takes place when a company's asset value falls to the debt's value. ${ }^{17}$

Under the Definition 2, when a company's net cash flow is negative, shareholders can decide whether to inject further equity capital in order to meet the company's debt obligations or to default. As long as they issue new capital and pay the interest rate they can exploit a future recovery in profitability. This means that, under unsecured debt finance, shareholders behave as if they owned a put option, whose exercise leads to default. ${ }^{18}$

\footnotetext{
${ }^{15}$ In the original Devereux-Griffith model, economic and fiscal depreciation allowances coincide, whereas in our model they may differ.

${ }^{16}$ For further details on default conditions see also Brennan and Schwartz (1977).

${ }^{17}$ As pointed out by Smith and Warner (1979, p. 127) "[s]ecuring debt gives bondholders title to pledged assets until the bonds are paid in full".

${ }^{18}$ In this article, we assume that default happens the first time a firm's cash flow crosses the threshold point. Yıldırım (2006) introduces an alternative definition of default, according to which default occurs when a firm's value process spends an exogenously given amount of time below the threshold point. This is an interesting topic that we leave for further research.
} 
Let us next calculate the value of equity. Using (2), applying Itô's Lemma and rearranging we obtain:

$$
(r+\lambda) E^{j}(\Pi ; C)=\Pi^{N}(\Pi ; C)+\frac{\sigma^{2}}{2} \Pi^{2} E_{\Pi \Pi}(\Pi ; C) \text { for } \Pi>\widetilde{\Pi}^{j}
$$

Solving (6) we obtain (see Appendix A):

$$
E^{j}(\Pi ; C)= \begin{cases}0 & \Pi<\widetilde{\Pi}^{j}, \\ \Psi(\Pi ; C)-\Psi\left(\widetilde{\Pi}^{j} ; C\right)\left(\frac{\Pi}{\widetilde{\Pi}^{j}}\right)^{\beta_{2}(\lambda)} & \Pi>\widetilde{\Pi}^{j},\end{cases}
$$

with $j=s, u$, and where $\Psi(\Pi ; C) \equiv \frac{(1-\tau)(\Pi-C)+\tau \lambda_{F} I}{r+\lambda}$, and $\beta_{2}(\lambda)=\frac{1}{2}-$ $\sqrt{\left(\frac{1}{2}\right)^{2}+\frac{2(r+\lambda)}{\sigma^{2}}}<0$. The term $\Psi(\Pi ; C)$ accounts for a scenario where no change occurs, apart for the future death of the project. As can be seen, the relevant discount rate is $r+\lambda$ instead of $r$. The reason is explained by Dixit and Pindyck (1994, p. 200): to deal with a stochastic decay of capital "we can regard the project as infinite-live, but augment the rate at which future profits are discounted by adding the Poisson death parameter". The latter term measures the contingent value of default. In particular, $\left(\Pi / \widetilde{\Pi}^{j}\right)^{\beta_{2}(\lambda)}$ measures the present value of 1 Euro contingent on the event default, and $\Psi\left(\widetilde{\Pi}^{j} ; C\right)$ is the expected present value of the profit lost by shareholders after expropriation.

We can now calculate the default threshold points under secured and unsecured debt, respectively.

Secured debt According to Definition 1, full debt protection means that the default threshold point $\widetilde{\Pi}^{s}$ must be such that we have $\Pi^{N}\left(\widetilde{\Pi}^{s} ; C\right)=$ 0, which implies that:

$$
\widetilde{\Pi}^{s}=C-\frac{\tau}{1-\tau} \lambda_{F} I
$$

Unsecured debt To calculate the threshold value under unsecured debt we follow Leland (1994). Therefore, $\widetilde{\Pi}^{u}$ is obtained by maximizing the value of equity, i.e.,

$$
\max _{\widetilde{\Pi}^{u}} E(\Pi, C) .
$$


Solving problem (9) (see Appendix B), we obtain:

$$
\widetilde{\Pi}^{u}=\frac{\beta_{2}(\lambda)}{\beta_{2}(\lambda)-1} \widetilde{\Pi}^{s}<\widetilde{\Pi}^{s}
$$

The inequality $\widetilde{\Pi}^{u}<\widetilde{\Pi}^{s}$ can be explained as follows: under unsecured debt finance, a company can inject equity in order to meet its debt obligations. This means that, contrary to the secured-debt-finance case, a company can postpone default and therefore, the contingent cost of default is lower under unsecured debt, i.e., $\left(\Pi / \widetilde{\Pi}^{u}\right)^{\beta_{2}(\lambda)}<\left(\Pi / \widetilde{\Pi}^{s}\right)^{\beta_{2}(\lambda)}$.

Following the same procedure, we can now calculate the value of debt. As shown in Appendix C, we obtain:

$$
D^{j}(\Pi ; C)= \begin{cases}\frac{(1-\tau) \Pi}{r+\lambda}+\tau \frac{\lambda_{F} I}{r+\lambda} & \Pi<\widetilde{\Pi}^{j} \\ \frac{C}{r+\lambda}+\left[\frac{(1-\tau) \widetilde{\Pi}^{j}}{r+\lambda}+\tau \frac{\lambda_{F} I}{r+\lambda}-\frac{C}{r+\lambda}-v C\right]\left(\frac{\Pi}{\widetilde{\Pi}^{j}}\right)^{\beta_{2}(\lambda)} & \Pi>\widetilde{\Pi}^{j}\end{cases}
$$

If $\Pi>\widetilde{\Pi}^{j}$, the value of debt consists of two terms: a perpetual rent and a term that is non-linear in $\Pi$. As we can see, the lender's relevant discount rate is $r+\lambda$ : this means that debt maturity is in line with the expected lifetime of investment. The second term measures the contingent value of the net cost of default. After default (i.e., when $\Pi$ has reached $\widetilde{\Pi}^{j}$ ), the lender becomes shareholder and the value of his company is equal to $\left[\frac{(1-\tau) \widetilde{\Pi}^{j}+\tau \lambda_{F} I}{r+\lambda}\right]$.

Substituting (7) and (11) into (4) gives a company's NPV:

$$
V^{j}(\Pi ; C)=V_{U}(\Pi ; C)+B^{j}(C),
$$

where

$$
V_{U}(\Pi)=\frac{(1-\tau) \Pi}{r+\lambda}-(1-\Omega \tau) I
$$

is the value of an unlevered company, $\Omega \equiv \frac{\lambda_{F}}{r+\lambda}$ is the present value of fiscal depreciation allowances, and

$$
B^{j}(C)=\left\{\tau-[\tau+(r+\lambda) v]\left(\frac{\Pi}{\widetilde{\Pi}^{j}}\right)^{\beta_{2}(\lambda)}\right\} \frac{C}{r+\lambda}, \text { with } j=s, u,
$$


is the net benefit of debt finance. ${ }^{19}$ As can be seen, $B^{j}(C)$ depends on both the tax rate and the default cost. ${ }^{20}$ In particular, it accounts for the fact that in the event of default, the tax benefit of interest deductibility is lost.

Let us next calculate the effective tax rate. Using (15), and setting $\tau=0$, we obtain the before-tax NPV:

$$
V_{P T}(\Pi ; C)=\frac{\Pi}{r+\lambda}-I-\left(\frac{\Pi}{\widetilde{\Pi}^{j}}\right)^{\beta_{2}(\lambda)} v C, \text { with } j=s, u,
$$

where $\left(\Pi / \widetilde{\Pi}^{j}\right)^{\beta_{2}(\lambda)} v C$ measures the expected cost of default. Substituting (12) and (14) into (5), and rearranging gives:

$$
E T R^{j}=\tau \frac{\frac{\Pi}{r+\lambda}-\Omega I-\left[1-\left(\frac{\Pi}{\widetilde{\Pi}^{j}}\right)^{\beta_{2}(\lambda)}\right] \frac{C}{r+\lambda}}{\frac{\Pi-\lambda I}{r+\lambda}}, \text { with } j=s, u \text {. }
$$

Let us next compare $E T R^{j}$ with a standard measure of effective taxation. In the spirit of Devereux and Griffith (1999), let us omit default costs and so we can write:

$$
E T R_{z d}=\tau \frac{\frac{\Pi}{r+\lambda}-\Omega I-\frac{C}{r+\lambda}}{\frac{\Pi-\lambda I}{r+\lambda}}
$$

where $z d$ stands for 'zero default'. By comparing (15) with (16), we can say that:

Proposition 1 For any coupon $C$, we have

$$
E T R^{j}-E T R_{z d}=\tau\left(\frac{\Pi}{\widetilde{\Pi}^{j}}\right)^{\beta_{2}(\lambda)} \frac{C}{\Pi-\lambda I}>0 .
$$

\footnotetext{
${ }^{19}$ To understand better the term $B^{j}(C)$, let us compare (12) with the Modigliani-Miller Formula, according to which the value of a levered company is equal to $V=V_{U}+\tau D$, where $V_{U}$ is the value of the unlevered company, and $D$ is the value of debt (see Modigliani and Miller, 1963, p. 440). According to the Modigliani-Miller approach, interest deductibility raises the value of a levered firm by an amount equal to $\tau$ times the value of debt. This means that the Modigliani-Miller Formula implicitly disregards the expected the cost of default. Whenever we account for the contingent cost of default, we must substitute $\tau D$ with $B^{j}(C)$, and we thus obtain (12).

${ }^{20}$ Maximizing the benefit function $B^{j}(C)$ we could obtain the optimal coupon under both secured and unsecured, namely, $C^{u}$ and $C^{s}$. As shown in Panteghini (2007a) we have $C^{u}>C^{s}$. The reasoning behind this result is as follows: under unsecured debt financing a company can decide when to default. Given its higher financial flexibility therefore, a company can choose a higher leverage ratio.
} 
As shown in Proposition 1, the standard measure $E T R_{z d}$ is biased, in that it disregards the expected cost of default and therefore overestimates the net benefit of debt finance. Eq. (15) also shows that the ETR crucially depends on the characteristics of debt as well as on the ratio between interest payments and a company's EBIT (Earnings Before Interest and Taxes), i.e., $C /(\Pi-\lambda I)$.

Notice that with Eq. (15) we can deal with either pure equity or pure debt finance. In the first case, we simply set $C=0$. In the second case, we set $C=C^{\max }$, where $C^{\max }$ is such that $D^{j}\left(\Pi ; C^{\max }\right)=I$. Of course, we can deal with an intermediate case if $C \in\left(0, C^{\max }\right) \cdot{ }^{21}$

It is worth noting that the relevant ETR crucially depends on whether debt is secured or unsecured. Given $\left(\Pi / \widetilde{\Pi}^{u}\right)^{\beta_{2}(\lambda)}<\left(\Pi / \widetilde{\Pi}^{s}\right)^{\beta_{2}(\lambda)}$, we can say that:

Proposition 2 For any coupon $C$, the inequality $E T R^{u}<E T R^{s}$ holds.

The reasoning behind Proposition 2 is simple: given (15) we can say that the higher the expected cost of default, the higher the effective tax rate is. Since under unsecured debt finance, a company delays default, the expected cost of default is lower than under secured debt. As a consequence, the effective tax rate is lower under unsecured than under secured debt finance.

Propositions 1 and 2 show that it is necessary to account for the characteristics of debt, i.e., the likelihood of default, maturity, and the existence of collateral (i.e., the default condition applied), to obtain an unbiased measure of the ETR.

\section{Hybrid securities}

In this section we calculate the ETR when a company issues two well-known hybrid securities: convertible and reverse convertible bonds. As we know, the holder of a convertible bond owns a call option that allows him to convert the bond into equity. ${ }^{22}$ When a company issues a reverse convertible bond,

\footnotetext{
${ }^{21}$ The intermediate case is in line with Boadway et al. (1984), who assume mixed finance and provide a measure of the ETR derived from the use of the Weighted Average Cost of Capital.

${ }^{22} \mathrm{~A}$ convertible bond usually has a relatively low coupon rate. This is due to the fact that the bondholder receives not only a coupon but also owns a call option, that allows
} 
the issuer, rather than the bondholder, has the right to convert this bond into equity. In this case, shareholders own a put option whose exercise leads to the conversion of debt into equity. ${ }^{23}$ In this latter case, the issuer (i.e., the company) can repay the bond either in cash or in shares. If the value of the underlying share is low enough, the issuer repays the bond in shares. ${ }^{24}$ By dealing with hybrid securities therefore, we implicitly focus on an investment project which can be jointly financed by debt and equity. ${ }^{25}$

For simplicity we assume that no capital gains tax is paid in the event of conversion. $^{26}$

\subsection{Convertible bonds}

Although convertible bonds are a well-know financial instrument and their use is widespread, they have not been considered to measure effective taxation. Contingent claim analysis allows us to calculate the fair value of convertible bonds and so to measure the ETR when a company issues this security. ${ }^{27}$

Let us define the default threshold point as $\underline{\Pi}$, and denote $\bar{\Pi}$ as the trigger point above which the bondholder's option is exercised. For simplicity, we assume that convertible debt is secured. ${ }^{28}$ This means that default takes place at point:

$$
\underline{\Pi}=\widetilde{\Pi}^{s} .
$$

Let us also introduce the following:

him to convert the bond into equity. For a detailed analysis of convertible bonds see, e.g., Brennan and Schwartz (1977), and Ingersoll (1977).

${ }^{23}$ As explained by Laukkanen (2007), the underlying asset of reverse convertible bonds can be the share of either the issuer or of a third listed company.

${ }^{24} \mathrm{~A}$ reverse convertible bond usually has a relatively high coupon rate. This high coupon compensates the bondholder for the put option owned by the issuer. Since this option is exercised if the shares underlying the option have fallen below a given level, the bondholder will receive the equity rather than the principal and will lose any additional coupons.

${ }^{25}$ This is in the spirit of Boadway et al. (1984).

${ }^{26}$ Laukkanen (2007) provides a detailed analysis of the tax treatment of capital gains arising from conversion.

${ }^{27}$ We could extend our analysis by assuming the joint use of equity, pure debt and convertible bonds. However, the quality of results would not change.

${ }^{28}$ The quality of results does not change if we assume that convertible debt is unsecured, i.e., shareholders can decide whether to inject further equity capital or not. Calculations are available from the author. 
Assumption 9 The bondholder has a call option to convert debt into equity. When he exercises this option, he acquires an exogenously given share of equity capital equal to $\gamma \in(0,1)$.

According to Assumption 9, the bondholder can decide when to exercise his call option namely, he chooses $\bar{\Pi}$. For simplicity, we assume that $\gamma$ is exogenously given. ${ }^{29}$ Following the same procedure of section 3 , we can write the value of equity and debt, respectively, as:

$$
E_{c}(\Pi ; C)= \begin{cases}0 & \Pi<\underline{\Pi}, \\ \Psi(\Pi ; C)+\sum_{i=1}^{2} A_{i} \Pi^{\beta_{i}(\lambda)} & \Pi \in(\underline{\Pi}, \bar{\Pi}), \\ (1-\gamma) W(\bar{\Pi}) & \Pi>\bar{\Pi},\end{cases}
$$

and

$$
D_{c}(\Pi ; C)= \begin{cases}\frac{(1-\tau) \Pi}{r+\lambda}+\tau \frac{\lambda_{F} I}{r+\lambda} & \Pi<\underline{\Pi}, \\ \frac{C}{r+\lambda}+\sum_{i=1}^{2} D_{i} \Pi^{\beta_{i}(\lambda)} & \Pi \in(\underline{\Pi}, \bar{\Pi}), \\ \gamma W(\bar{\Pi}) & \Pi>\bar{\Pi},\end{cases}
$$

with $\beta_{1}(\lambda)=\frac{1}{2}+\sqrt{\left(\frac{1}{2}\right)^{2}+\frac{2(r+\lambda)}{\sigma^{2}}}>1$, and where $W(\bar{\Pi})=\frac{(1-\tau) \bar{\Pi}+\tau \lambda_{F} I}{r+\lambda}$ is a perpetual rent that measures the value of a company in the absence of future changes (apart from the stochastic decay of investment). If we compare (19) and (20) with (7) and (11), respectively, we can see that, under convertible bond finance, both the equity and the debt function have now a third branch. This is due to the expected conversion of debt into equity. When $\Pi$ reaches $\bar{\Pi}$, the bondholder finds it optimal to exercise the option to convert. By exercising this option the bondholder acquires a share of the company which is worth $\gamma W(\bar{\Pi})$, and loses any future flow of coupons. After the conversion, the shareholder's claim reduces to a $(1-\gamma) W(\bar{\Pi})$.

\footnotetext{
${ }^{29}$ Notice that $\gamma$ might be the result of a bargaining process, which would involve different stakeholders (see, e.g., Hennessy and Tserlukevich, 2005). This topic is beyond the scope of our article.
} 
Using (19) and (20) we obtain:

$$
\begin{aligned}
V_{c}(\Pi ; C)= & \frac{(1-\tau) \Pi+\tau C}{r+\lambda}-(1-\Omega \tau) I \\
& +\sum_{i=1}^{2}\left(A_{i}+D_{i}\right) \Pi^{\beta_{i}(\lambda)},
\end{aligned}
$$

which accounts for three future events: default, conversion and the sudden death of the investment project. It is worth noting that under convertible debt finance, we have no closed-form solution: Appendix D therefore discusses the boundary conditions needed to obtain a numerical solution for $A_{i}$, $D_{i}$, with $i=1,2$, and $\bar{\Pi}$.

Despite the absence of a closed-form solution, we can discuss the effects of contingent-claim evaluation on the effective tax rate. Using (21) and setting $\tau=0$ we obtain the pre-tax net present value:

$$
V_{P T, c}(\Pi ; C)=\frac{\Pi}{r+\lambda}+\sum_{i=1}^{2}\left(\left.A_{i}\right|_{\tau=0}+\left.D_{i}\right|_{\tau=0}\right) \Pi^{\beta_{i}(\lambda)}-I .
$$

Substituting (21) and (22) into (5) gives the ETR under convertible debt finance:

$$
E T R_{c}=E T R_{z d}+\phi_{c}(\tau, \Pi)
$$

where

$$
\phi_{c}(\tau, \Pi) \equiv \frac{\sum_{i=1}^{2}\left[\left(\left.A_{i}\right|_{\tau=0}-A_{i}\right)+\left(\left.D_{i}\right|_{\tau=0}-D_{i}\right)\right] \Pi^{\beta_{i}(\lambda)}}{\frac{\Pi-\lambda I}{r+\lambda}} .
$$

As shown in $(23), \phi_{c}(\tau, \Pi)$ measures the bias of $E T R_{z d}$. Such a bias is due to the sum of four terms, that depend on the fact that contingent evaluation of future events under taxation differs from that in the absence of taxation. In particular, the term $\left(\left.A_{1}\right|_{\tau=0}-A_{1}\right) \Pi^{\beta_{1}(\lambda)}$ measures the tax wedge due to shareholders' expected loss after the conversion of debt into equity: in this case, the existing shareholders lose a fraction $\gamma$ of their company, which is then acquired by the ex bondholders. The term $\left(\left.A_{2}\right|_{\tau=0}-A_{2}\right) \Pi^{\beta_{2}(\lambda)}$ measures the tax wedge regarding shareholders' loss faced in the event of default. The other two terms regard bondholders. In particular, $\left(\left.D_{1}\right|_{\tau=0}-D_{1}\right) \Pi^{\beta_{1}(\lambda)}$ measures the tax wedge related to bondholders' gain due to the exercise of the option to convert. Finally, $\left(\left.D_{2}\right|_{\tau=0}-D_{2}\right) \Pi^{\beta_{2}(\lambda)}$ accounts for bondholders' expected loss in the event of default. 


\subsection{Reverse convertible bonds}

A reverse convertible bond gives the issuer the right to convert equity. In other terms, the bond's issuer (i.e., the shareholder) owns a put option, whose exercise leads to the conversion of debt into a company's shares. ${ }^{30}$

Denoting $\widehat{\Pi}$ as the threshold point above which conversion is made, we can write the value of equity as:

$$
E_{r c}(\Pi ; C)= \begin{cases}(1-\gamma) W(\widehat{\Pi}) & \Pi<\widehat{\Pi}, \\ \Psi(\Pi ; C)+\sum_{i=1}^{2} A_{i} \Pi^{\beta_{i}(\lambda)} & \Pi \in(\widehat{\Pi}, \infty),\end{cases}
$$

where $W(\widehat{\Pi})=\left[(1-\tau) \frac{\widehat{\Pi}}{r+\lambda}+\frac{\tau \lambda_{F} I}{r+\lambda}\right]$. As we can see, $E_{r c}(\Pi ; C)$ has two branches. If $\Pi \in(\widehat{\Pi}, \infty)$, shareholders find it optimal to pay a coupon $C$ to bondholders. When $\Pi$ reaches $\widehat{\Pi}$, shareholders exercise the option to convert debt into equity. After the exercise, shareholders' claim therefore reduces to $(1-\gamma) W(\widehat{\Pi})$

As we know, if $\Pi \in(\widehat{\Pi}, \infty)$ the bondholder receives $C$. However, he must account for the fact that in the future, $\Pi$ may drop to $\widehat{\Pi}$. In this case, he will receive a share of the company, whose value is $\gamma W(\widehat{\Pi})$, thereby losing any opportunity to receive the coupon. Accordingly, we can write the value of debt as:

$$
D_{r c}(\Pi ; C)= \begin{cases}\gamma W(\widehat{\Pi}) & \Pi<\widehat{\Pi}, \\ \frac{C}{r+\lambda}+\sum_{i=1}^{2} D_{i} \Pi^{\beta_{i}(\lambda)} & \Pi>\widehat{\Pi} .\end{cases}
$$

As shown in Appendix E, the value of equity and debt can be written as:

$$
E_{r c}(\Pi ; C)= \begin{cases}(1-\gamma) W(\widehat{\Pi}) & \Pi<\widehat{\Pi}, \\ {\left[\frac{(1-\tau)(\Pi-C)+\tau \lambda_{F} I}{r+\lambda}\right]+A_{2} \Pi^{\beta_{2}(\lambda)}} & \Pi \in(\widehat{\Pi}, \infty),\end{cases}
$$

\footnotetext{
${ }^{30}$ In this article we assume that the underlying asset is the issuer's equity shares.
} 
and

$$
D_{r c}(\Pi ; C)= \begin{cases}\gamma W(\widehat{\Pi}) & \Pi<\widehat{\Pi}, \\ \frac{C}{r+\lambda}+\left\{\gamma\left[\frac{(1-\tau) \widehat{\Pi}}{r+\lambda}+\tau \frac{\lambda_{F} I}{r+\lambda}\right]-\frac{C}{r+\lambda}\right\}\left(\frac{\Pi}{\widehat{\Pi}}\right)^{\beta_{2}(\lambda)} & \Pi \in(\widehat{\Pi}, \infty),\end{cases}
$$

where

$$
\widehat{\Pi}=\frac{\beta_{2}(\lambda)}{\beta_{2}(\lambda)-1}\left[\frac{C}{\gamma}-\frac{\tau}{1-\tau} \lambda_{F} I\right]
$$

measures the trigger point below which shareholders find it optimal to exercise their put option. We can therefore say that, if $\gamma \in(0,1), \widehat{\Pi}>\widetilde{\Pi}^{u}$. In other terms, the conversion of debt into equity takes place before the event of default under pure debt finance. If $\gamma=1$, we have $\widehat{\Pi}=\widetilde{\Pi}^{u}$. This means that unsecured debt is a special case of reverse convertible bond. ${ }^{31}$

Substituting (26) and (27) into (4), and rearranging gives the NPV:

$$
V_{r c}(\Pi ; C)=\frac{(1-\tau) \Pi}{r+\lambda}-(1-\tau \Omega) I+\tau\left[1-\left(\frac{\Pi}{\widehat{\Pi}}\right)^{\beta_{2}(\lambda)}\right] \frac{C}{r+\lambda} .
$$

Using (28) and setting $\tau=0$, we obtain the zero-tax NPV:

$$
V_{P T, r c}(\Pi ; C)=\frac{\Pi}{r+\lambda}-I .
$$

Substituting (28) and (29) into (5) gives:

$$
E T R_{r c}=E T R_{z d}+\tau \frac{C}{\Pi-\lambda I}\left(\frac{\Pi}{\widehat{\Pi}}\right)^{\beta_{2}(\lambda)} .
$$

Again, the ETR accounts for the contingent value of conversion. If we compare (17) with (30) we can see that the ETR has the same form, although the contingent-claim term differs. Given the inequality $\widehat{\Pi}>\widetilde{\Pi}^{u}$ (for $\gamma \in(0,1)$ ), we have $(\Pi / \widehat{\Pi})^{\beta_{2}(\lambda)}>\left(\Pi / \widetilde{\Pi}^{u}\right)^{\beta_{2}(\lambda)}$. This means that $E T R_{r c}>E T R^{u}$ for any $C$. Moreover, it is easy to see that $\frac{\partial E T R_{r c}}{\partial \gamma}<0$ : in other words, an increase in $\gamma$ reduces the trigger point $\widehat{\Pi}$, and therefore lowers the expected cost of default. This causes a decrease in $E T R_{r c}$. When $\gamma$ goes to 1 , the reverse convertible bond is equivalent to unsecured debt and therefore, $E T R_{r c}$ collapses to ETR ${ }^{u}$.

\footnotetext{
${ }^{31}$ Depending on the value of $\gamma$, the trigger point $\widehat{\Pi}$ may be higher or lower than $\widetilde{\Pi}^{s}$.
} 


\begin{tabular}{|l|l|}
\hline Parameter & Value \\
\hline$C$ & 1 \\
\hline$I$ & 20 \\
\hline$r$ & 0.04 \\
\hline$\sigma$ & 0.2 \\
\hline$\lambda$ & 0.05 \\
\hline$\gamma$ & 0.03 \\
\hline$\Pi$ & $1.8,2.6$ \\
\hline$\lambda_{F}$ & $\lambda$ \\
\hline
\end{tabular}

Table 1: The parameter values for numerical simulations

\section{A numerical analysis}

To give a feeling of how the ETR depends on parameter values, we present some numerical example. As shown in Table 1 , we set $r=0.04$ and $\sigma=$ 0.20, which represent the benchmark assumptions used by Dixit and Pindyck (1994, p. 153) and are consistent with empirical evidence. ${ }^{32}$ Moreover, we assume that the depreciation rate $\lambda$ is $0.05 .{ }^{33}$ We also assume that, in the event of conversion of a hybrid security, the bondholder receives $30 \%$ of the company (i.e., $\gamma=0.3$ ). Moreover we will calculate the ETRs under two alternative values of $\Pi$, i.e., 1.8 and 2.6. The former value means that a company's ROI (i.e., the ratio between $\Pi-\lambda I$ and $I$ ) is equal to 0.04 (i.e., the risk-free interest rate $r$ ); with $\Pi=1.8$, we therefore calculate the marginal ETR. The latter value entails a higher ROI, i.e., 0.09, which overcomes the risk-free rate. In this case, we have a measure of the average ETR. For simplicity, we will also assume that fiscal depreciation allowances coincide with economic depreciation (i.e., $\lambda_{F}=\lambda$ ). In what follows, we will also make some sensitivity analysis regarding parameters $\sigma, \gamma, \lambda, C$.

As shown in Figures 1 and 2, under pure debt finance, a change in $C$ has an ambiguous impact on the ETR. If $C$ is low enough, an increase in leverage reduces the ETR. When however $C$ reaches an intermediate point, a further increase in leverage raises the ETR. This U-shaped effect is due to

\footnotetext{
${ }^{32}$ See, e.g., Jorion and Goetzman (1999) and Dimson et al. (2002).

${ }^{33}$ Notice that $\lambda$ usually ranges from 0 to 0.10 . This range is in line with the average depreciation rates reported in Fixed Reproducible Tangible Wealth in the United States, 1925-1989 (10\% for equipment and 5\% for structures) and is applied, e.g., by Caballero and Engels (1999).
} 
two offsetting effects: the first one is the benefit of tax deductions, while the second one is related to the contingent value of the default cost. If therefore $C$ is low, an increase in leverage guarantees a relatively large tax saving in terms of deductibility, and causes a small increase in the contingent value of default costs. Given the low level of leverage, the probability of default is low and therefore, the former effect dominates the latter. When however $C$ goes beyond a given level, the converse is true, namely, we have a small increase in tax savings, and a large increase in the contingent value of default costs. This leads to an increase in the ETR.

Let us next compare Figures 1 and 2. We can see that, in line with Proposition 1, the inequality $E T R^{s}>E T R^{u}$ always holds. Under unsecured debt finance, the ETR may be negative (see Figure 2). This is due to the fact that the contingent cost of default is lower under unsecured than under secured debt finance. Given the tax benefit of interest deductibility, a company is thus subsidized if $C$ ranges from about 2 to 3 .

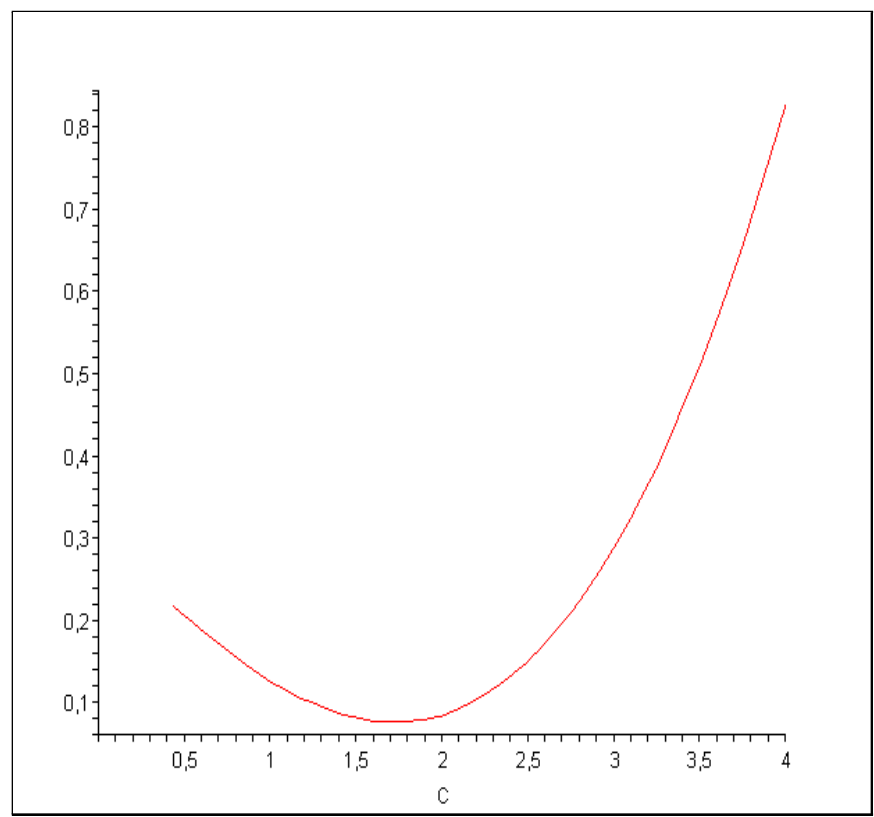

Figure 1: The effect of a change in $C$ on $E T R^{s}$ (secured debt) 


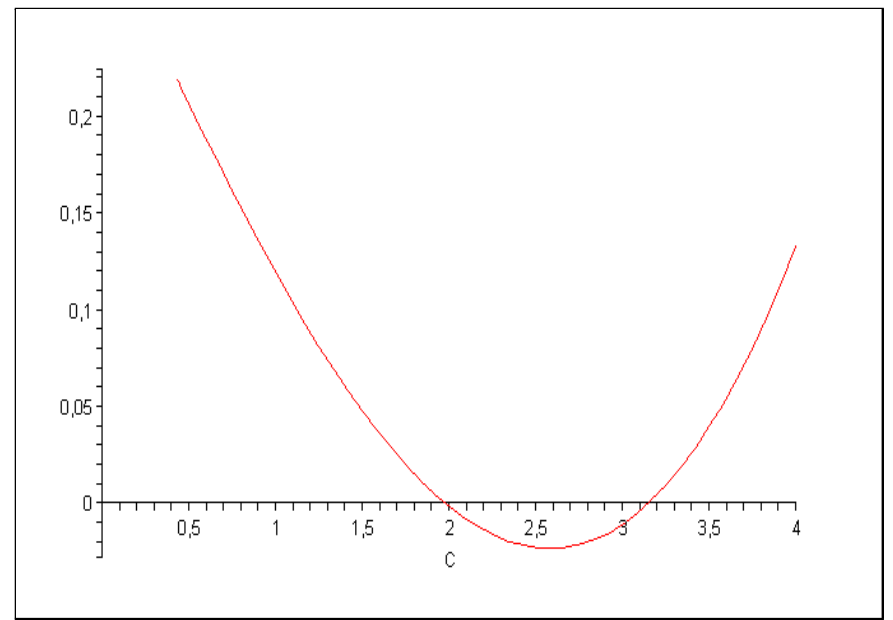

Figure 2: The effect of a change in $C$ on $E T R^{u}$ (unsecured debt)

Figures 3 and 4 show the effect of an increase in $\lambda$. As can be seen, the higher the parameter $\lambda$, the lower the ETR. This is due to the fact that, given $\lambda_{F}=\lambda$, an increase in $\lambda$ leads to more generous fiscal depreciation allowances. However, there is a second offsetting effect, that has been disregarded by the existing literature: namely, debt maturity. As we pointed out, a higher $\lambda$ means a shorter debt maturity. We can therefore say that, for any $\Pi_{0}$, the higher the parameter $\lambda$, the shorter the maturity of debt and the higher the probability of default is. As shown in Figures 3 and 4, however, the former effect dominates the maturity effect. When $\lambda$ is higher than 0.08, the ETR becomes negative under both secured and unsecured debt finance. 


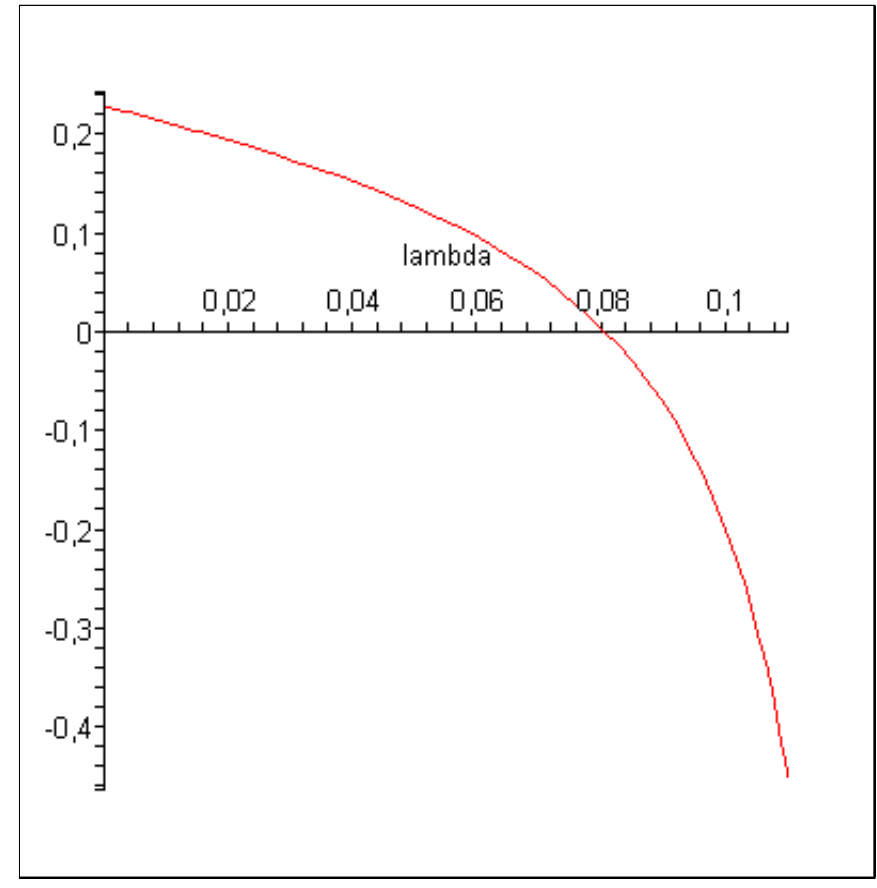

Figure 3: The effect of a change in $\lambda$ on $E T R^{s}$ (secured debt)



Figure 4: The effect of a change in $\lambda$ on $E T R^{u}$ (unsecured debt) 
Figures 5 and 6 show that an increase in $\sigma$ raises the ETR. The reason is simple: coeteris paribus, an increase in volatility raises the probability of default. This means that the contingent cost of default increases with volatility and therefore, leads to a higher ETR.

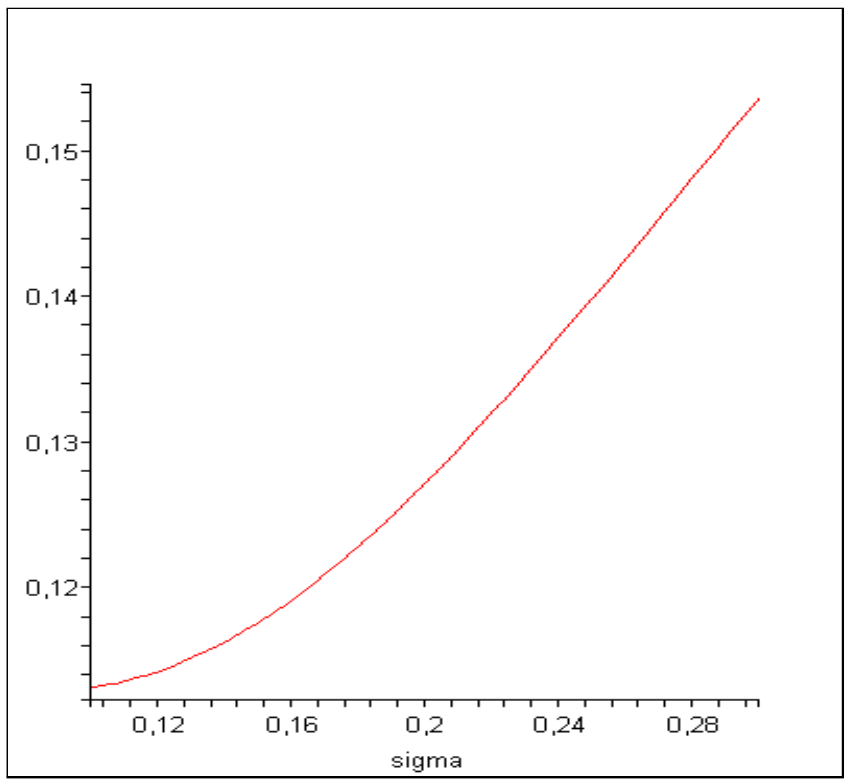

Figure 5: The effect of a change in $\sigma$ on $E T R^{s}$ (secured debt)

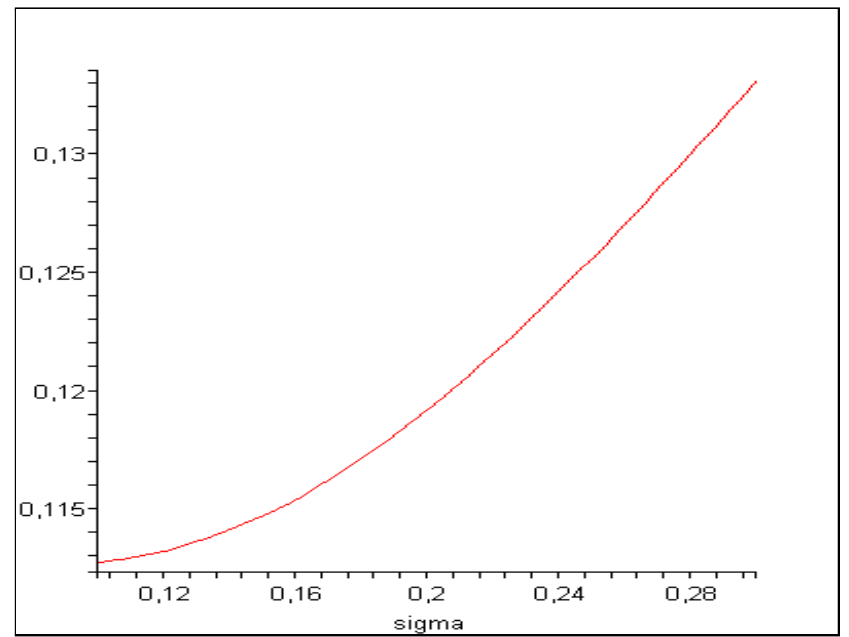

Figure 6: The effect of a change in $\sigma$ on $E T R^{u}$ (unsecured debt) 
Let us next focus on hybrid securities. Since we have no closed-form solution under convertible bond finance, Figure 7 shows how the values of $A_{i}, D_{i}$, with $i=1,2$, and $\bar{\Pi}$ vary with the statutory tax rate. We can also see that:

- $\left(\left.A_{1}\right|_{\tau=0}-A_{1}\right) \Pi^{\beta_{1}(\lambda)}$, i.e., the tax wedge due to shareholders' expected loss in terms of profit, is negative;

- $\left(\left.A_{2}\right|_{\tau=0}-A_{2}\right) \Pi^{\beta_{2}(\lambda)}$, i.e., the tax wedge regarding shareholders' loss faced in the event of default, is positive;

- $\left(\left.D_{1}\right|_{\tau=0}-D_{1}\right) \Pi^{\beta_{1}(\lambda)}$, i.e., the tax wedge related to bondholders' gain due to the exercise of the option to convert, is positive;

- $\left(\left.D_{2}\right|_{\tau=0}-D_{2}\right) \Pi^{\beta_{2}(\lambda)}$, i.e., the tax wedge related to bondholders' expected loss in the event default, is negative.

As shown in Figure 7, an increase in the tax rate raises point $\bar{\Pi}$, i.e., induces a postponement of conversion. The reason is straightforward: for any $\Pi$, the higher the tax rate, the lower a company's after-tax cash flow is. This means that the relative advantage of becoming shareholder is negatively affected by the tax rate. 

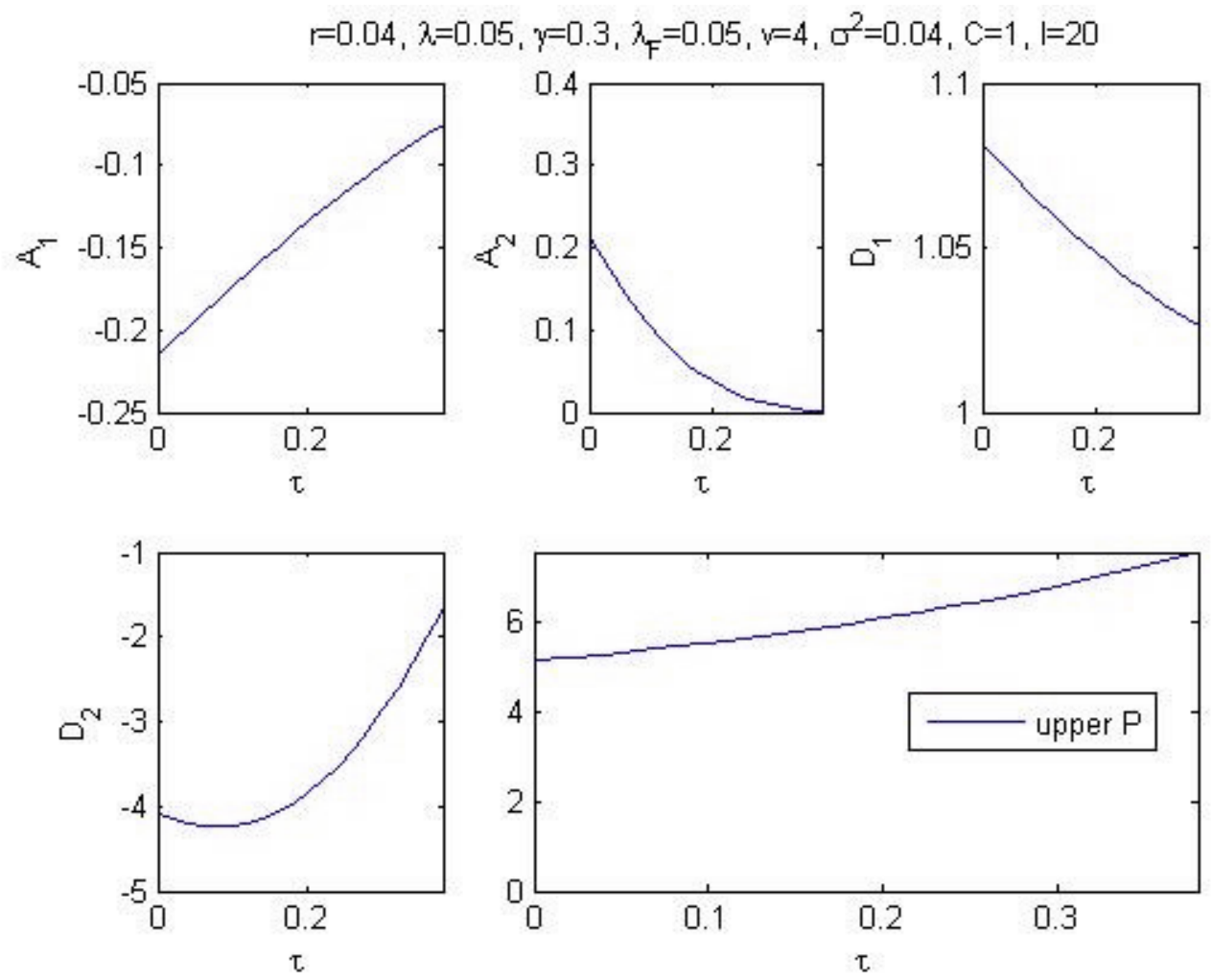

Figure 7: The effect of a tax rate change on $A_{i}, D_{i}$, with $i=1,2$, and $\bar{\Pi}$, under convertible debt.

In Figure 8 we compare the standard measure $E T R_{z d}$, with the ETR obtained under both convertible and reverse convertible debt. We assume that $\Pi=1.8$ (i.e., $\frac{\Pi-\lambda I}{I}=r$ ). As we can see, both $E T R_{z d}$ and $E T R_{r c}$ are negative. Moreover, the higher the statutory rate, the larger the bias is. 


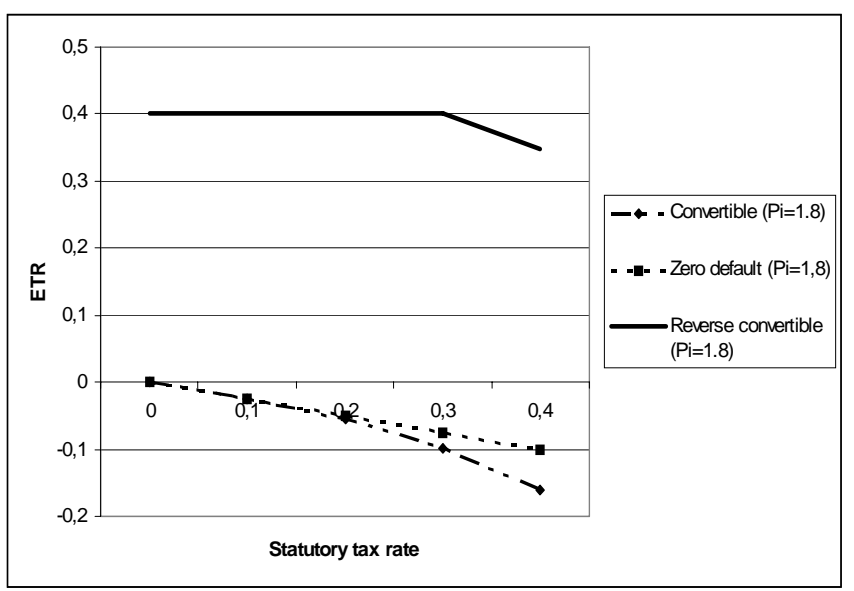

Figure 8: The effect of an increase in the statutory tax rate on the ETR

$$
(\Pi=1.8)
$$

Figure 8 also shows the effect of a change in the statutory tax rate on $E T R_{r c}$. As we can see, the equality $E T R_{r c}=\tau$ holds for $\tau \leq 0.3158$. This is due to the fact that, if the statutory tax rate is low enough (i.e., $\tau \leq$ 0.3158 ), we have $\Pi \leq \widehat{\Pi}$. In other words, conversion has already occurred, and therefore, we have a fully equity financed company. In this case the ETR is equal to the statutory tax rate. When $\tau$ rises however, conversion has not already occurred (i.e., $\Pi>\widehat{\Pi}$ ): this means that a company enjoys from the tax benefit of interest deductibility, at least for some time. As we can see, the bias $\left(E T R_{r c}-E T R_{z d}\right)$ is more than $100 \%$ of the statutory tax rate.

Figure 9 shows the effects of an increase in $\tau$ on $E T R_{z d}, E T R_{c}$, and $E T R_{r c}$, with $\Pi=2.6$ (i.e., $\frac{\Pi-\lambda I}{I}=0.009>r$ ). In this case the ETRs are all positive. As we can see, the higher the statutory rate, the larger the bias is. 




Figure 9: The effect of an increase in the statutory tax rate on the ETR

$$
(\Pi=2.6)
$$

Finally, it is worth noting that, in both Figures 8 and 9 (i.e., for different values of a firm's ROI) the inequalities $E T R_{r c}>E T R_{z d}>E T R_{c}$ hold. As we have shown in (30), we have $E T R_{r c}>E T R_{z d}$. This inequality is due to the fact that $E T R_{r c}$ embodies the contingent impact of conversion, that reduces the tax advantage of debt. The inequality $E T R_{z d}>E T R_{c}$ is due to the fact that the overall tax wedge $\phi_{c}(\tau, \Pi)$ of Eq. (23) is negative. This means that the contingent evaluation of conversion and default under taxation is less than that obtained in the absence of taxation.

\section{Conclusion}

In this article we have applied contingent-claim analysis to provide a forwardlooking measure of effective taxation that accounts for default, debt maturity, and the conversion of debt into equity. In particular, we have calculated the ETR under secured and unsecured debt finance, and we have also provided a measure of the ETR under convertible and reverse convertible bond issue. We have shown that our contingent-claim ETR can dramatically differ from standard ones.

The contingent-claim measure of the ETR can be extended by considering other hybrid securities. Moreover, in this article we have used many simplifying assumptions, such as tax symmetry, the absence of agency costs 
and of any bargaining process between stakeholders (including renegotiation). Of course, the elimination of any of these simplifying assumptions is an interesting topic for future research. 


\section{A The derivation of (7)}

Solving (6) one obtains

$$
E^{j}(\Pi ; C)= \begin{cases}0 & \Pi<\widetilde{\Pi}^{j}, \\ {\left[(1-\tau) \frac{\Pi-C}{r+\lambda}+\frac{\tau \lambda_{F} I}{r+\lambda}\right]+\sum_{i=1}^{2} A_{i} \Pi^{\beta_{i}(\lambda)}} & \Pi>\widetilde{\Pi}^{j},\end{cases}
$$

where $\beta_{1}(\lambda)=\frac{1}{2}+\sqrt{\left(\frac{1}{2}\right)^{2}+\frac{2(r+\lambda)}{\sigma^{2}}}>1$ and $\beta_{2}(\lambda)=\frac{1}{2}-\sqrt{\left(\frac{1}{2}\right)^{2}+\frac{2(r+\lambda)}{\sigma^{2}}}<0$ are the roots of the characteristic Eq. $\Psi(\beta)=\frac{1}{2} \sigma^{2} \beta(\beta-1)-(r+\lambda)=0$. As can be seen, the before-default value of equity consists of two terms: the perpetual rent, in square brackets, and $\sum_{i=1}^{2} A_{i} \Pi^{\beta_{i}(\lambda)}$. Let us next calculate $A_{1}$ and $A_{2}$. In the absence of any financial bubbles, $A_{1}$ is nil (see Dixit and Pindyck, 1994). Therefore, setting $A_{1}=0$ we can rewrite (31) as

$$
E^{j}(\Pi ; C)= \begin{cases}0 & \text { after default } \\ {\left[(1-\tau)\left(\frac{\Pi-C}{r+\lambda}\right)+\frac{\tau \lambda_{F} I}{r+\lambda}\right]+A_{2} \Pi^{\beta_{i}(\lambda)}} & \text { before default. }\end{cases}
$$

To calculate $A_{2}$, we must notice that when default occurs, i.e., when $\Pi$ drops to $\widetilde{\Pi}^{j}$, we have

$$
E\left(\widetilde{\Pi}^{j} ; C\right)=0
$$

with $\widetilde{\Pi}^{j}=\widetilde{\Pi}^{s}, \widetilde{\Pi}^{u}$, because the firm is expropriated by the lender. Substituting (32) into (33) we find $A_{2}$, and rearranging we obtain (7).

\section{B The derivation of (10)}

Using (7) and differentiating (9) gives the following f.o.c.

$$
\begin{aligned}
& \frac{\partial E^{u}(\Pi)}{\partial \widetilde{\Pi}^{u}}=-\frac{(1-\tau)}{\delta+\lambda}\left(\frac{\Pi}{\widetilde{\Pi}^{u}}\right)^{\beta_{2}(\lambda)} \\
& +\beta_{2}(\lambda)\left[(1-\tau) \frac{\widetilde{\Pi}^{u}-C}{r+\lambda}+\frac{\tau \lambda_{F} I}{r+\lambda}\right]\left(\frac{\Pi}{\widetilde{\Pi}^{u}}\right)^{\beta_{2}(\lambda)}\left(\widetilde{\Pi}^{u}\right)^{-1}=0 .
\end{aligned}
$$

Rearranging (34) one obtains (10). 


\section{The derivation of (11)}

Using (3), applying Itô's Lemma and rearranging gives:

$$
(r+\lambda) D^{j}(\Pi ; C)= \begin{cases}{\left[(1-\tau) \Pi+\tau \lambda_{F} I\right]+\frac{\sigma^{2}}{2} \Pi^{2} D_{\Pi \Pi}(\Pi ; C)} & \Pi<\widetilde{\Pi}^{j} \\ C+\frac{\sigma^{2}}{2} \Pi^{2} D_{\Pi \Pi}(\Pi ; C) & \Pi>\widetilde{\Pi}^{j}\end{cases}
$$

Solving (35) one obtains:

$$
D^{j}(\Pi ; C)= \begin{cases}\frac{(1-\tau) \Pi}{r+\lambda}+\tau \frac{\lambda_{F} I}{r+\lambda}+\sum_{i=1}^{2} B_{i} \Pi^{\beta_{i}(\lambda)} & \Pi<\widetilde{\Pi}^{j}, \\ \frac{C}{r+\lambda}+\sum_{i=1}^{2} D_{i} \Pi^{\beta_{i}(\lambda)} & \Pi>\widetilde{\Pi}^{j},\end{cases}
$$

where terms $\sum_{i=1}^{2} B_{i} \Pi^{\beta_{i}(\lambda)}$ and $\sum_{i=1}^{2} D_{i} \Pi^{\beta_{i}(\lambda)}$ measure the contingent value of future events after and before default, respectively. To calculate $B_{2}$ we use the boundary condition $D^{j}(0 ; C)=0$, which means that when $\Pi$ falls to zero, the lender's post-default claim is nil, and so we have $B_{2}=0$. In the absence of any financial bubble, we also have $B_{1}=D_{1}=0$. To calculate $D_{2}$ we let the pre-default branch of (36) meet with its after-default one, net of the default cost $v C$, at point $\Pi=\widetilde{\Pi}^{j}$, with $j=s$, u, i.e.,

$$
\frac{C}{r+\lambda}+D_{2} C^{\beta_{2}(\lambda)}=\left[\frac{(1-\tau) \widetilde{\Pi}^{j}}{r+\lambda}+\tau \frac{\lambda_{F} I}{r+\lambda}\right]-v C .
$$

Solving (37) for $D_{2}$ gives

$$
D_{2}=\left[\frac{(1-\tau) \widetilde{\Pi}}{r+\lambda}+\tau \frac{\lambda_{F} I}{r+\lambda}-\frac{C}{r+\lambda}-v C\right] \widetilde{\Pi}^{j^{-\beta_{2}(\lambda)}}, \text { with } j=s, u,
$$

and substituting this solution into (36) one obtains (11).

\section{Convertible bonds}

In order to calculate the value of convertible bonds, the following conditions must hold. Firstly, we know that, under default, expropriation occurs. Using Eq. (19) we can write: 


$$
E_{c}(\underline{\Pi} ; C)=\left[(1-\tau) \frac{\underline{\Pi}-C}{r+\lambda}+\frac{\tau \lambda_{F} I}{r+\lambda}\right]+\sum_{i=1}^{2} A_{i} \underline{\Pi}^{\beta_{i}(\lambda)}=0 .
$$

Secondly, the second and third branch of function $E_{c}(\Pi ; C)$ meet at point $\Pi=\bar{\Pi}$, i.e., we have

$$
\left[(1-\tau) \frac{\bar{\Pi}-C}{r+\lambda}+\frac{\tau \lambda_{F} I}{r+\lambda}\right]+\sum_{i=1}^{2} A_{i} \bar{\Pi}^{\beta_{i}(\lambda)}=(1-\gamma)\left[(1-\tau) \frac{\bar{\Pi}}{r+\lambda}+\frac{\tau \lambda_{F} I}{r+\lambda}\right]
$$

Thirdly, when default takes place, the value of debt is equal to the value of the company, net of the default cost. Using (20) we can write:

$$
\frac{C}{r+\lambda}+\sum_{i=1}^{2} D_{i} \underline{\Pi}^{\beta_{i}(\lambda)}=\frac{(1-\tau) \underline{\Pi}}{r+\lambda}+\tau \frac{\lambda_{F} I}{r+\lambda}-v C .
$$

Fourthly, when conversion occurs, the second and third branch of (20) meet at point $\Pi=\bar{\Pi}$, i.e.,

$$
\frac{C}{r+\lambda}+\sum_{i=1}^{2} D_{i} \bar{\Pi}^{\beta_{i}(\lambda)}=\gamma\left[(1-\tau) \frac{\bar{\Pi}}{r+\lambda}+\frac{\tau \lambda_{F} I}{r+\lambda}\right]
$$

We also know that the bondholder can optimally decide when to convert, namely he chooses point $\bar{\Pi}$. Following Dixit and Pindyck (1994), we thus introduce a Smooth Pasting Condition (SPC), where the second and third branch of (20) meet tangentially at point $\Pi=\bar{\Pi}$. Since the SPC requires the equality between the slope of these two branches we have:

$$
\frac{\partial\left[\frac{C}{r+\lambda}+\sum_{i=1}^{2} D_{i} \bar{\Pi}^{\beta_{i}(\lambda)}\right]}{\partial \bar{\Pi}}=\gamma \frac{\partial\left[(1-\tau) \frac{\bar{\Pi}}{r+\lambda}+\frac{\tau \lambda_{F} I}{r+\lambda}\right]}{\partial \bar{\Pi}},
$$

which gives:

$$
\sum_{i=1}^{2} \beta_{i}(\lambda) D_{i} \bar{\Pi}^{\beta_{i}(\lambda)-1}=\frac{\gamma(1-\tau)}{r+\lambda} .
$$

Solving the system (38), (39), (40), (41), (42), we obtain $\bar{\Pi}, A_{1}, A_{2}, D_{1}, D_{2}$. 


\section{E Reverse convertible bonds}

Let us first focus on equity. We know that, in the absence of bubbles, we have $A_{1}=0$. Moreover, applying the VMC and SPC to (24), we obtain:

$$
\begin{gathered}
{\left[(1-\tau) \frac{\widehat{\Pi}-C}{r+\lambda}+\frac{\tau \lambda_{F} I}{r+\lambda}\right]+A_{2} \widehat{\Pi}^{\beta_{2}(\lambda)}=(1-\gamma)\left[\frac{(1-\tau) \widehat{\Pi}}{r+\lambda}+\frac{\tau \lambda_{F} I}{r+\lambda}\right]} \\
\frac{1-\tau}{r+\lambda}+\beta_{2}(\lambda) A_{2} \widehat{\Pi}^{\beta_{2}(\lambda)-1}=(1-\gamma) \frac{1-\tau}{r+\lambda}
\end{gathered}
$$

Solving (43) and (44) for $\widehat{\Pi}$ and $A_{2}$ gives

$$
\widehat{\Pi}=\frac{\beta_{2}(\lambda)}{\beta_{2}(\lambda)-1}\left[\frac{C}{\gamma}-\frac{\tau}{1-\tau} \lambda_{F} I\right]
$$

and

$$
A_{2}=-\frac{\gamma(1-\tau)}{\beta_{2}(\lambda)(r+\lambda)} \widehat{\Pi}^{1-\beta_{2}(\lambda)} .
$$

The value of equity is thus equal to (26).

Let us next calculate the value of debt. In the absence of bubbles we have $D_{1}=0$. Let equate the two branches of (25). We obtain:

$$
\frac{C}{r+\lambda}+D_{2} \widehat{\Pi}^{\beta_{2}(\lambda)}=\gamma W(\widehat{\Pi})
$$

which gives

$$
D_{2}=\left[\gamma W(\widehat{\Pi})-\frac{C}{r+\lambda}\right] \widehat{\Pi}^{-\beta_{2}(\lambda)} .
$$

Using the solution for $D_{2}$ and rearranging gives (27). 


\section{References}

[1] Boadway R., N. Bruce and J. Mintz (1984), Taxation, Inflation, and the Effective Marginal Tax Rate on Capital in Canada, Canadian Journal of Economics, 17, pp. 62-79.

[2] Branch B. (2002), The Costs of Bankruptcy: A Review, International Review of Financial Analysis, 11, pp. 39-57.

[3] Brennan M.J. and E.S. Schwartz (1977), Convertible Bonds: Valuation and Optimal Strategies for Call and Conversion, Journal of Finance, 32, pp. 1699-1715.

[4] Caballero R.J. and E.M.R. Engel (1999), Explaining Investment Dynamics in U.S. Manufacturing: A Generalized $(S, s)$ Approach, Econometrica, 67, pp. 783-826.

[5] Devereux M.P. (2003), Measuring Taxes on Income from Capital, in P.B. Sørensen (ed.), Measuring the Tax Burden on Capital and Labor, CESifo Seminar Series, The MIT Press.

[6] Devereux M.P. and R. Griffith (1999), The Taxation of Discrete Investment Choices, Institute for Fiscal Studies, IFS Working Papers: W98/16.

[7] Dimson E., P. Marsh and M. Staunton (2002) Triumph of the Optimists, Princeton University Press: Princeton, New Jersey.

[8] Dixit A. and R.S. Pindyck (1994), Investment under Uncertainty, Princeton University Press.

[9] Eckhardt T. (2007), Germany, Tax Notes International, December 31, 2007, pp. 1356-1358.

[10] Galeano G.A. and A.M. Rhode (2008), Italy: 2008 Budget Law Reduces Corporate Tax Rate, but Expands Tax Base, Tax Planning International Review, 35, pp. 18-22.

[11] Giannini S. and C. Maggiulli (2002), Effective Tax Rates in the EU Commission Study on Company Taxation: Methodological Aspects, Main Results and Policy Implications, Ifo Studien, 48, pp. 633-653. 
[12] Goldstein R., N. Ju and H. Leland (2001), An EBIT-Based Model of Dynamic Capital Structure, Journal of Business, 74, pp. 483-512.

[13] Gordon R., L. Kalambokidis and J. Slemrod (2003), A New Summary Measure of the Effective Tax Rate on Investment, in P.B. Sørensen (ed.), Measuring the Tax Burden on Capital and Labor, CESifo Seminar Series, The MIT Press.

[14] Graham J.R. and C.R. Harvey (2001), The Theory and Practice of Corporate Finance: Evidence from the Field, Journal of Financial Economics, 60, pp. 187-243.

[15] Gray D., C.H. Lim, E. Loukoianova and S. Malone (2008), A RiskBased Debt Sustainability Framework: Incorporating Balance Sheets and Uncertainty, IMF Working Paper 08/40.

[16] Hennessy C. and Y. Tserlukevich (2005), Analyzing Callable and Convertible Bonds when the Modigliani-Miller Assumptions are Violated, EFA 2005 Moscow Meetings Paper.

[17] Hennessy C. and T.M. Whited (2005), Debt Dynamics, Journal of Finance, 60, pp. 1129-1165.

[18] Ingersoll J. (1977), An Examination of Corporate Call Policies on Convertible Securities, Journal of Finance, 32, pp. 463-478.

[19] Jensen M. (1986), Agency Costs of Free Cash Flow, Corporate Finance, and Takeovers, American Economic Review, 76, pp. 323-329.

[20] Jorion P. and W.N. Goetzman (1999), Global Stock Markets in the Twentieth Century, Journal of Finance, 54, pp. 953-980.

[21] Laukkanen A. (2007), Taxation and Investment Derivatives, IBFD, Amsterdam.

[22] Leland H.E. (1994), Corporate Debt Value, Bond Covenants, and Optimal Capital Structure, Journal of Finance, September, 49, pp. 12131252.

[23] McDonald R.L. (2004), The Tax (Dis)advantage of a Firm Issuing Options on Its Own Stock, Journal of Public Economics, 88, pp. 925-955. 
[24] McDonald R. and D. Siegel (1985), Investment and the Valuation of Firms When There is an Option to Shut Down, International Economic Review, 26, pp. 331-349.

[25] McDonald R. and D. Siegel (1986), The Value of Waiting to Invest, Quarterly Journal of Economics, 101, pp. 707-728.

[26] Modigliani F. and M.H. Miller (1963), Corporate Income Taxes and the Cost of Capital: A Correction, American Economic Review, 53, pp. 433-443.

[27] Niemann R. and C. Sureth (2005), Capital Budgeting with Taxes under Uncertainty and Irreversibility, Jahrbucher fur Nationalokonomie und Statistik, 225, pp. 77-95.

[28] Panteghini P.M. (2006), S-Based Taxation under Default Risk, Journal of Public Economics, 90, pp. 1923-1937.

[29] Panteghini P.M. (2007a), Corporate Taxation in a Dynamic World, Springer.

[30] Panteghini P.M. (2007b), Interest Deductibility under Default Risk and the Unfavorable Tax Treatment of Investment Costs: A Simple Explanation, Economics Letters, 96, pp.1-7.

[31] Ross S.A. (2005), Capital Structure and the Cost of Capital, Journal of Applied Finance, 15, pp. 5-23.

[32] Smith C.W. Jr. and J.B. Warner (1979), On Financial Contracting: An Analysis of Bond Covenants, Journal of Financial Economics, 7, pp. $117-161$.

[33] Sørensen P.B. (2003), Measuring Taxes on Capital and Labor: An Overview of Methods and Issues, in P.B. Sørensen (ed.), Measuring the Tax Burden on Capital and Labor, CESifo Seminar Series, The MIT Press.

[34] Yıldırım Y. (2006), Modeling Default Risk: A New Structural Approach, Finance Research Letters, 3, pp. 165-172. 


\section{CESifo Working Paper Series}

for full list see www.cesifo-group.org/wp

(address: Poschingerstr. 5, 81679 Munich, Germany, office@cesifo.de)

2269 Thomas Aronsson and Erkki Koskela, Outsourcing and Optimal Nonlinear Taxation: A Note, April 2008

2270 Gary E. Bolton, Claudia Loebbecke and Axel Ockenfels, How Social Reputation Networks Interact with Competition in Anonymous Online Trading: An Experimental Study, April 2008

2271 Nikolaus Wolf, Scylla and Charybdis. Explaining Europe’s Exit from Gold, January 1928 - December 1936, April 2008

2272 Michael Funke and Marc Gronwald, The Undisclosed Renminbi Basket: Are the Markets Telling us something about where the Renminbi - US Dollar Exchange Rate is Going?, April 2008

2273 Thor Olav Thoresen and Annette Alstadsæter, Shifts in Organizational Form under a Dual Income Tax System, April 2008

2274 Helge Berger and Volker Nitsch, Too many Cooks? Committees in Monetary Policy, April 2008

2275 Yin-Wong Cheung and Eiji Fujii, Deviations from the Law of One Price in Japan, April 2008

2276 Michael S. Michael, Sajal Lahiri and Panos Hatzipanayotou, Integrated Reforms of Indirect Taxes in the Presence of Pollution, April 2008

2277 Bas Jacobs, Is Prescott Right? Welfare State Policies and the Incentives to Work, Learn and Retire, April 2008

2278 Burkhard Heer and Alfred Maußner, Value Function Iteration as a Solution Method for the Ramsey Model, April 2008

2279 Jarko Fidrmuc and Christa Hainz, Integrating with their Feet: Cross-Border Lending at the German-Austrian Border, April 2008

2280 Kristof Dascher and Alexander Haupt, The Political Economy of Regional Integration Projects at Borders where Rich and Poor Meet: The Role of Cross-Border Shopping and Community Sorting, April 2008

2281 Katrin Assenmacher-Wesche and M. Hashem Pesaran, A VECX* Model of the Swiss Economy, April 2008

2282 Christophe Rault, Robert Sova and Ana Maria Sova, Modeling International Trade Flows between CEEC and OECD Countries, April 2008 
2283 Timo Boppart, Josef Falkinger, Volker Grossmann, Ulrich Woitek and Gabriela Wüthrich, Qualifying Religion: The Role of Plural Identities for Educational Production, April 2008

2284 Armin Falk, David Huffman and W. Bentley MacLeod, Institutions and Contract Enforcement, April 2008

2285 Axel Dreher and Stefan Voigt, Does Membership in International Organizations Increase Governments' Credibility? Testing the Effects of Delegating Powers, April 2008

2286 Xavier Freixas and Bruno M. Parigi, Lender of Last Resort and Bank Closure Policy, April 2008

2287 Regina Dionisius, Samuel Muehlemann, Harald Pfeifer, Günter Walden, Felix Wenzelmann and Stefan C. Wolter, Cost and Benefit of Apprenticeship Training - A Comparison of Germany and Switzerland, April 2008

2288 Francesco Daveri and Cecilia Jona-Lasinio, Off-Shoring and Productivity Growth in the Italian Manufacturing Industries, April 2008

2289 Mikael Priks, Do Surveillance Cameras Affect Unruly Behavior? A Close Look at Grandstands, April 2008

2290 Marianna Belloc and Daniela Federici, A Two-Country NATREX Model for the Euro/Dollar, April 2008

2291 Nicolas Treich, The Value of a Statistical Life under Ambiguity Aversion, April 2008

2292 J. Atsu Amegashie, Socially-Tolerable Discrimination, April 2008

2293 M. Hashem Pesaran and Andreas Pick, Forecasting Random Walks Under Drift Instability, April 2008

2294 Steven Brakman, Gus Garita, Harry Garretsen and Charles van Marrewijk, Unlocking the Value of Cross-Border Mergers and Acquisitions, May 2008

2295 Eric O’N. Fisher and Kathryn G. Marshall, The Structure of the American Economy, May 2008

2296 Claudia M. Buch and Martin Schlotter, Regional Origins of Employment Volatility: Evidence from German States, May 2008

2297 Helmuth Cremer, Philippe De Donder, Dario Maldonado and Pierre Pestieau, Taxing Sin Goods and Subsidizing Health Care, May 2008

2298 Reinhilde Veugelers and Frederick van der Ploeg, Reforming European Universities: Scope for an Evidence-Based Process, May 2008 
2299 Jon H. Fiva and Lars J. Kirkebøen, Does the Housing Market React to New Information on School Quality?, May 2008

2300 Tina Klautke and Alfons J. Weichenrieder, Interest Income Tax Evasion, the EU Savings Directive, and Capital Market Effects, May 2008

2301 Harald Badinger and Peter Egger, GM Estimation of Higher Order Spatial Autoregressive Processes in Panel Data Error Component Models, May 2008

2302 Jan K. Brueckner, Slot-Based Approaches to Airport Congestion Management, May 2008

2303 Sören Blomquist, Vidar Christiansen and Luca Micheletto, Public Provision of Private Goods and Nondistortionary Marginal Tax Rates, May 2008

2304 Dan Anderberg and Alessandro Balestrino, The Political Economy of Post-Compulsory Education Policy with Endogenous Credit Constraints, May 2008

2305 Tomer Blumkin, Yoram Margalioth and Efraim Sadka, The Role of Stigma in the Design of Welfare Programs, May 2008

2306 Vesa Kanniainen and Paolo M. Panteghini, Tax Neutrality: Illusion or Reality? The Case of Entrepreneurship, May 2008

2307 Thomas Dohmen, Armin Falk, David Huffman and Uwe Sunde, The Intergenerational Transmission of Risk and Trust Attitudes, May 2008

2308 Guglielmo Maria Caporale and Mario Cerrato, Using Chebyshev Polynomials to Approximate Partial Differential Equations, May 2008

2309 Peter Egger and Doina Maria Radulescu, Labour Taxation and Foreign Direct Investment, May 2008

2310 Laurent Linnemer, Dissipative Advertising Signals Quality even without Repeat Purchases, May 2008

2311 Jordi Jofre-Monseny and Albert Solé-Ollé, Which Communities should be afraid of Mobility? The Effects of Agglomeration Economies on the Sensitivity of Firm Location to Local Taxes, May 2008

2312 Andreas Haufler and Ferdinand Mittermaier, Unionisation Triggers Tax Incentives to Attract Foreign Direct Investment, May 2008

2313 Ronel Elul and Piero Gottardi, Bankruptcy: Is it enough to Forgive or must we also Forget?, May 2008

2314 Andreas Irmen and Johanna Kuehnel, Productive Government Expenditure and Economic Growth, May 2008 
2315 Beate Henschel, Carsten Pohl and Marcel Thum, Demographic Change and Regional Labour Markets: The Case of Eastern Germany, May 2008

2316 Gabriel Felbermayr, Wido Geis and Wilhelm Kohler, Restrictive Immigration Policy in Germany: Pains and Gains Foregone?, May 2008

2317 Michael Hofmann, Gerhard Kempkes and Helmut Seitz, Demographic Change and Public Sector Budgets in a Federal System, May 2008

2318 Paul De Grauwe, Macroeconomic Modeling when Agents are Imperfectly Informed, June 2008

2319 Johann K. Brunner and Susanne Pech, Optimum Taxation of Inheritances, June 2008

2320 Thomas Eichner and Marco Runkel, Corporate Income Taxation of Multinationals in a General Equilibrium Model, June 2008

2321 Rainald Borck and Matthias Wrede, Subsidies for Intracity and Intercity Commuting, June 2008

2322 Patricia Apps and Ray Rees, Testing the Pareto Efficiency of Household Resource Allocations, June 2008

2323 Amihai Glazer, Vesa Kanniainen and Panu Poutvaara, Firms' Ethics, Consumer Boycotts, and Signalling, June 2008

2324 Claudia M. Buch, Jörg Döpke and Kerstin Stahn, Great Moderation at the Firm Level? Unconditional vs. Conditional Output Volatility, June 2008

2325 Helmuth Cremer, Philippe De Donder, Dario Maldonado and Pierre Pestieau, Forced Saving, Redistribution and Nonlinear Social Security Schemes, June 2008

2326 M. Hashem Pesaran and Paolo Zaffaroni, Optimal Asset Allocation with Factor Models for Large Portfolios, June 2008

2327 Harald Badinger and Peter Egger, Horizontal versus Vertical Interdependence in Multinational Activity, June 2008

2328 Jan K. Brueckner and Harris Selod, A Theory of Urban Squatting and Land-Tenure Formalization in Developing Countries, June 2008

2329 Paolo M. Panteghini, Corporate Debt, Hybrid Securities and the Effective Tax Rate, June 2008 